MATEC Web of Conferences 22,04003 (2015)

DOI: $10.1051 /$ matecconf/ 20152204003

(C) Owned by the authors, published by EDP Sciences, 2015

\title{
Focus on Humanistic Values in Rural Livable Residential System
}

\author{
Xiuli Sun \\ School of Architecture \& Fine Art, Dalian University of Technology, Dalian, Liaoning, China \\ Chundong Ma \\ School of Design, Dalian Nationalities University, Dalian, Liaoning, China \\ Jian Tang* \\ School of Architecture \& Fine Art, Dalian University of Technology, Dalian, Liaoning, China
}

\begin{abstract}
We consider the development of farmers as a goal of residential system using value rationality instead of farmer's requirements which can be satisfied. Based upon the position and function of humanistic values in residential system, a rural housing system is built as a subjectivity and objectivity unity consisting of artifacts system, behavior system and concept system. Moreover, we introduce three coupling design strategies to rural livable residential system aiming to guide the current reconstruction of shabby buildings in rural areas.
\end{abstract}

Keywords: rural residential system; humanistic value; livability

\section{INTRODUCTION}

The rural residences in China are mainly self-built, as the owners are self-responsible for construction, living environment, building maintenance and energy supply. These works involve numerous primitive ecological self-organization and self-circulation activities $[1,2]$. Moreover, rural housings, which are an integration of residence and the part associated with local agricultural production, form its unique human settlement morphology. The differences in space and development laws separate rural residences from urban residences in terms of attributes and construction mode. Compared to the consumptive urban residences that mainly meet living demand, the rural residences are sustainable residences developed from the symbiosis between farmers and the living environment. However, according to the existing literatures and medium reports, the majority of rural dilapidated buildings are refurbished with the hope of creating livable residences through the replacement of old buildings with materials and crafts $[3,4]$. Farmers become passively adaptable to the alteration of living mode, and thus neglect their own values. Residences deviate from the context of rural life and lose the rural characteristics.

Livable residences means that farmers are pleased with their material base in terms of survival and spiritual enjoyment, and also the value recognition and the self-admiration through their own actions resulting from the new living environment. Moreover, in the practice, they have developed the behaviors and personality, and the improvement of their degree of civilization can promote the harmonious coexistence of human settlement relationships in rural areas.

\section{RURAL RESIDENTIAL SYSTEM UNDER VALUE RATIONALITY}

\subsection{Ideas of human settlement during construction of rural residences}

In the current ideas of rural residential designing, it is widely promoted to create an inhabitable environment favorable for body comfort and spiritual enjoyment through the construction of buildings, which sets meeting residential demand as the starting point and destination of residential construction, and shows some instrumental reason. Instrumental reason focuses on utilizing the efficacy of utensils at the cost of resources. Some high-tech buildings cause the new burden to farmers because of high cost in construction and maintenance. The low cost in rural life relative to urban life always makes farmers proud, and this life characteristic is usually achieved through abundant interaction between farmers and the living environment. For example, in traditional rural residences of Northeast China, the heating problem is solved by cooking on an open fire three times a day. This fact indicates that besides the utensils-level design, another efficient energy saving route is the design based on farmers' behaviors and concepts. Farmers play critical roles in indoor thermal control, house decoration, energy utilization, and the efficacy of facilities [5]. In solving the technical problems of these systems, more solutions will be available if attention is paid to the realization of humanistic values. Moreover, the farmers' behaviors and concepts will also be reshaped, and their quality be improved, which are favorable for the realization of livability.

* Corresponding author: Tan511@vip.sina.com

This is an Open Access article distributed under the terms of the Creative Commons Attribution License 4.0, which permits unrestricted use, distribution, and reproduction in any medium, provided the original work is properly cited. 


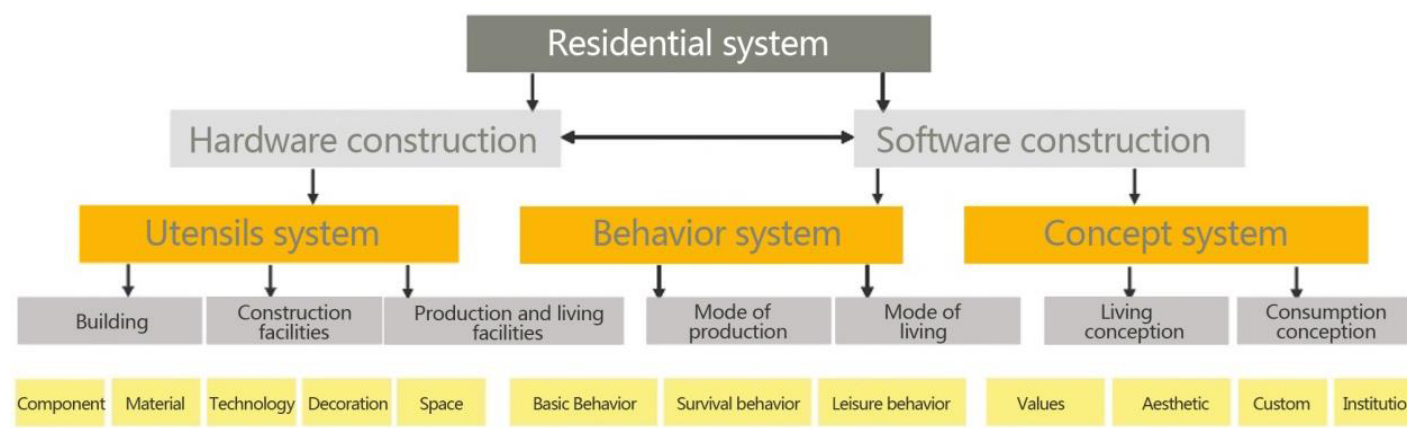

Figure1. Rural residential system

Table 1 . Housing Needs between Rural and City

\begin{tabular}{|c|c|c|}
\hline $\begin{array}{ll}\text { Type of } & \text { residence } \\
\text { Residential } \\
\text { demand }\end{array}$ & Rural residences & Urban residences \\
\hline Survival demand & \multicolumn{2}{|c|}{ Shelter; Eating; Rest; Temperature; Humidity; Lighting; Air } \\
\hline Common demand & $\begin{array}{l}\text { Low construction cost and high } \\
\text { Low residential cost and high lif } \\
\text { Low maintenance cost; } \\
\text { Privacy; } \\
\text { Neighborhood communication }\end{array}$ & $\begin{array}{l}\text { ruction quality; } \\
\text { lity; }\end{array}$ \\
\hline \multirow{7}{*}{ Personalized demand } & Promote dignity & Maintain dignity \\
\hline & Improve health conditions & Security protection \\
\hline & Improve infrastructure & Convenient traffic \\
\hline & Production and sideline & Leisure entertainment \\
\hline & Circular economy & Complete supporting services \\
\hline & Ecological energy conservation & Energy conservation facilities \\
\hline & Rural culture & Urban culture \\
\hline
\end{tabular}

2.2 Rural residential system under unification of subject and object

The integration of personal life, social life and rural environment is the unity from the joint action of architectural culture and rural residential culture. In this study, the construction of a rural livable residential system is divided into two parts: hardware construction and software construction (Figure 1). The hardware system is targeted at inhabitability and includes the subsystems of buildings, construction facilities and so on; the software system is targeted at livability and includes farmers' behaviors and concept design. Based on Yoshizaka's theory of three life modes [6], the hardware and software systems can be categorized into three dimensions: utensils system, behavior system, and concept system, which constitute the frame for research on the rural residences system. The software system is a guarantee for the hardware construction and efficacy realization, while the hardware sys- tem is the basis of software construction. There are interaction, and mutual promotion between the two systems and their subsystems and the elements. Study on any subsystem alone is meaningless. An effective method is to study the interaction mechanism among the three systems, so that the instrumental reason and value rationality are integrated into residential design and practice, which helps to achieve individual innovation and the target of system. Thereby, farmers can create a sustainable ecological residence with improved human settlement benefits.

\section{RESIDENTIAL DEMANDS BY A LIVABLE RESIDENTIAL SYSTEM}

Because of insufficient material basis and obsolete lifestyles as well as life concepts, rural people remind of laggard and poverty for a long time. Nevertheless, urban people still look forward to the self-organization of production, freedom of living arrangements, availa- 
bility of natural environment, and simple idea of energy conservation. In this study, we aim to clarify the research contents about the rural residence system and the livable connotations of interest. Therefore, we comparatively analyzed the residential demands between rural and urban residents. As showed in Table 1, the demands of rural residences include more interactions of humans with the residences and the natural environment.

The demands above correspond to the material and cultural factors in the residential system. For instance, the promotion of dignity through residences means that the farmers are allowed to enjoy necessary material achievements from modernization. Moreover, their way of thinking should be altered from the conventional identity identification to professional identification in terms of health consciousness, consciousness of environmental protection, and grade of rural amorous decoration. Therefore, the behaviors and personality of modern farmers should be cultivated. For another example, in the cold areas of North China, the improvement of sanitary conditions includes the construction hardware (toilet room, bathroom facilities, drainage sewer system, and indoor decoration), and attention should also be paid to the refurbishment costing and utilization of local resources. Measures should be taken to change the formers' outdated habits of eating, sleeping and entertainment on a Kang (heated brick bed). The relationships of humans with Kang, furniture, and function space should be planned and designed again. Matching design is needed to design building facilities and production/living facilities that are appropriate for local materials and economic conditions. The farmers should be guided to develop conscious or subconscious health habits and energy conservation behaviors.

\section{COUPLING DESIGN STRATEGIES FOR THE RURAL RESIDENCE SYSTEM}

The theory of coupling $[7,8]$ involves not only the characteristics of single systems, but also the characteristics and interactions among subsystems at the same level or at different levels. This theory helps to build new systems with optimized performance and thus is the methodology suitable for investigation into livable rural residential systems $[9,10]$. From this perspective, we provided guidance to the construction of a demonstration housing project in Piaojiagou Village in Chentun Town, Gaizhou City, Liaoning Province, China. We studied the self-coupling of buildings and techniques, the strain-reactive coupling and co-existence coupling between buildings and humans, and the strain-reactive coupling strategy based on behavior-conducive and ideas-conducive. We aim to create a livable system under mutual promotion and coordinated operation.

\subsection{Background of the Project}

The demonstration housing project is located in a monsoon belt, with the number of days at which the temperature is below $0^{\circ} \mathrm{C}$ being between 170 and 210 , annually. The extreme minimum temperature is approximately $-25^{\circ} \mathrm{C}$. The village is $37 \mathrm{~km}$ from Gaizhou city and is situated in a hilly and seismic zone. The water table can be found approximately 5 meters below the surface. The agricultural production method primarily involves using small mechanical devices, whereas the universal educational background of the farmers is at the primary school level. It was shown in the comparisons of the exterior of this house before and after retrofit (Figure 2), and the plans respectively (Figure 3, Figure 4).

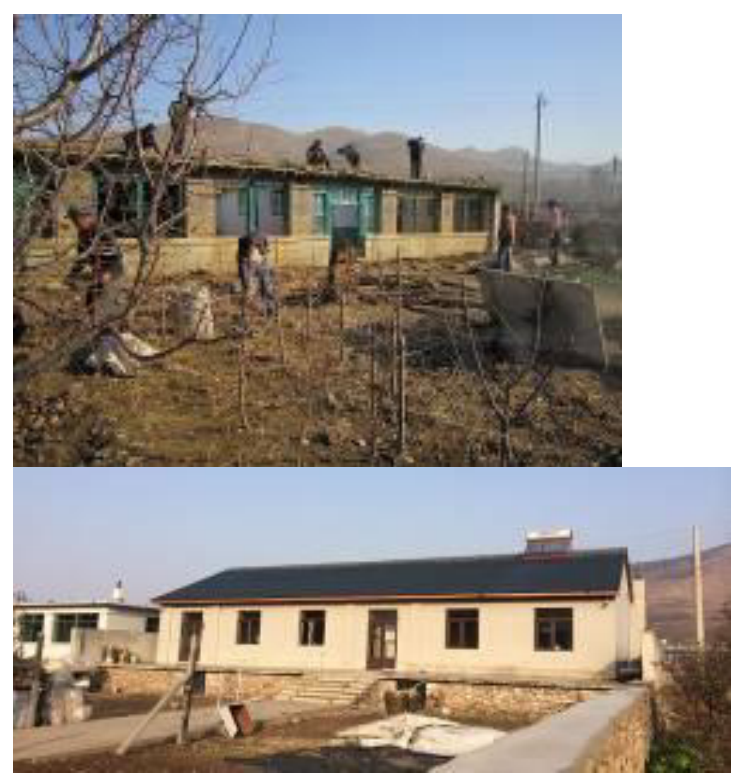

Figure 2. Exterior before and after Retrofit

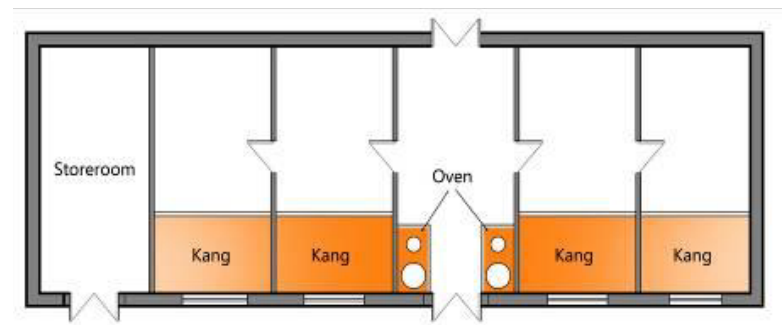

Figure 3. Plan before Retrofit 


\section{MATEC Web of Conferences}

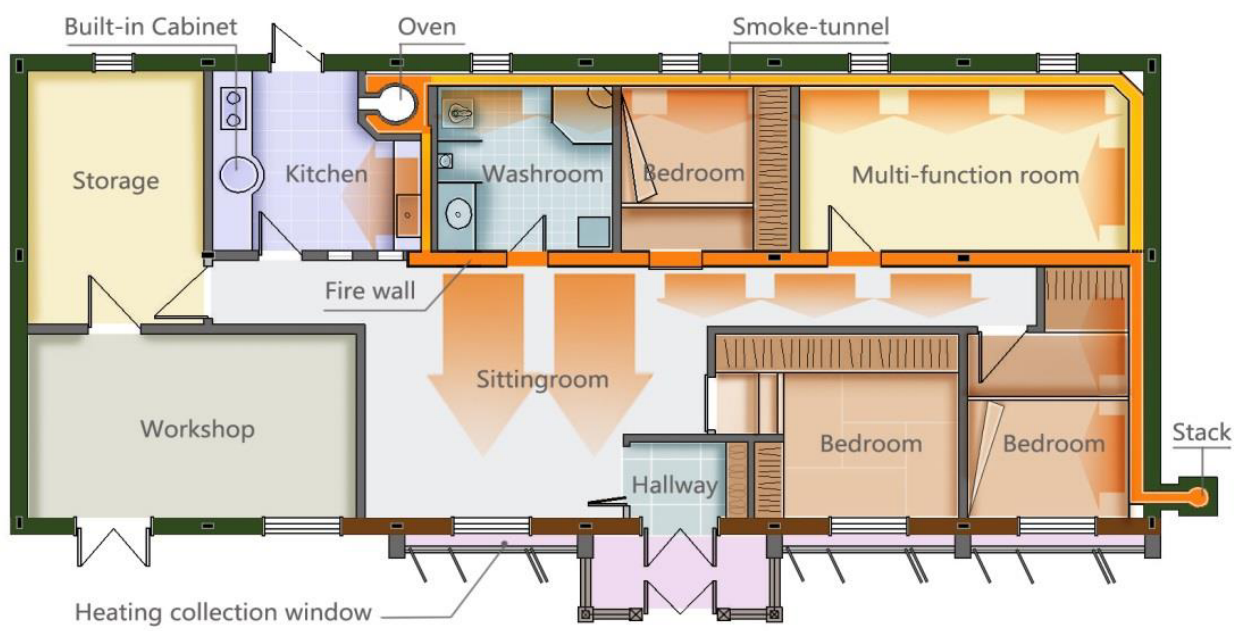

Figure 4. Plan after Retrofit

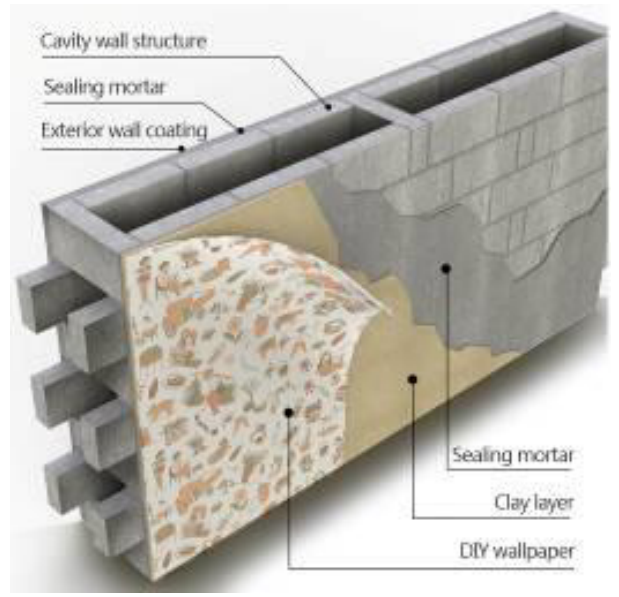

Figure 5. Prototype of Light-weight Wall

by using the price of the building material and labor in 2011, the construction cost (including decoration) is $1500 \mathrm{RMB} / \mathrm{m}^{2}$. Furthermore, the building the seismic fortification intensity is 8 degree. Since its construction and decoration, the house has been inhabited and undergone tests through three winters. The effort in our work essentially attempted to extract the realization of farmers' humanistic values in the residence system based on the internal connections between buildings, technology and occupants.

\subsection{Energy Saving Design of the Building}

Some passive energy-consumption building designs base on the actual consideration of the local consump-

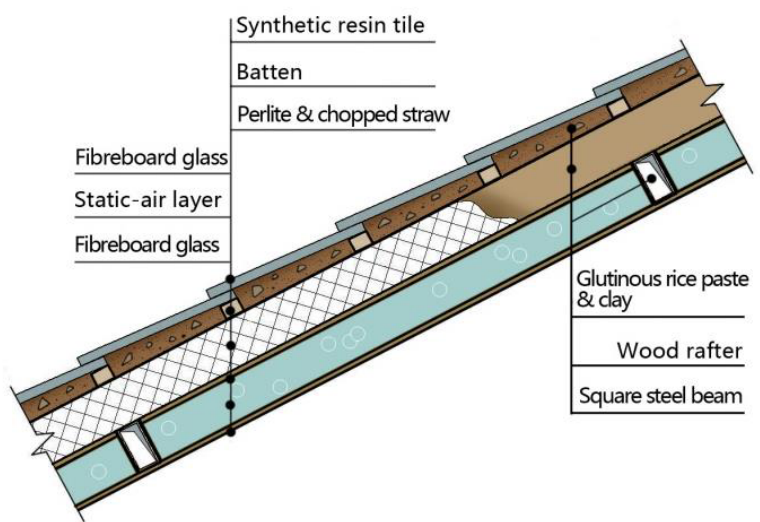

Figure 6. Section of New Roof

tion ability for housing were adopted to construct the building structures with less material, low cost, high degree of seismic resistance, and simple construction technology. For example, inheriting the form of traditional brick components for the building envelope, the red bricks were replaced with slag bricks and a new type of bricklaying as illustrated in Figure 5, where three horizontal bricks and one vertical brick form a type of new lightweight wall construction that is easy for the farmers themselves to build. Based on the stain-reactive coupling among the building and building materials, labor price and local natural resources, apart from some locally accessible materials, some materials of traditional roof, simple and viable construction methods were used for the new roof (Figure 6). 
On the basis of the characteristics of small plots of arable land per household, restricted outdoor activity during the cold winter months and the seasonal return of migrant workers in this village, we created conditions for farmers to undertake family artisanal sideline activities with strain-reactive space design, according to the coupling relationship between the functional space and the behavior-conducive. We planned for a workshop and warehouse space in the western aspect of the house for rural craftsmen to create local products and engage in handicrafts, or as a space where raw materials and tools could be stored. At the northeastern corner of the living zone, a multi-function room was established, which could not only be used as a temporary guest room, but also as a storage room for daily miscellaneous items. (See in Figure 4) Taking advantage of co-existence coupling and strain-reactive coupling, the decoration of the interior walls was through traditional craft of backing paper with common packing paper embodying local folklore characteristics and being delicately printed (Figure 7), installed by farmers themselves. This has an elegant appearance and involves reduced cost; moreover, the paper can be repaired or replaced at any time in order to save money on wall decoration and maintenance.

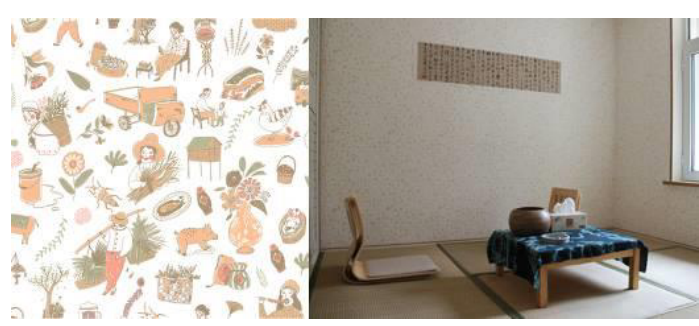

Figure 7. Photograph of Decoration of Interior Wall

\subsection{Thermal Environment Design of the Building}

To ensure the general thermal environment of the house is well maintained, we designed a new type of overall heating system to replace the traditional Kang-oven heating system, which included the self-coupling design among the heat-insulation wall, wallpaper, the heating collection windows, heat-insulation roof, eaves and damp-insulation floor; and the southward rest area. For example, the cold-bridge phenomenon is avoided due to the separation of the lightweight steel structure from the building enclosure (Figure 8); the heating collection windows (Figure 4) we designed are economic to save homestead and material than the common solar sunroom, it was derived by us with self-coupling design between the wall, windows and sunroom; and by sealing the corners of the rooms the wallpaper (Figure 7) can also function as a heat insulator.

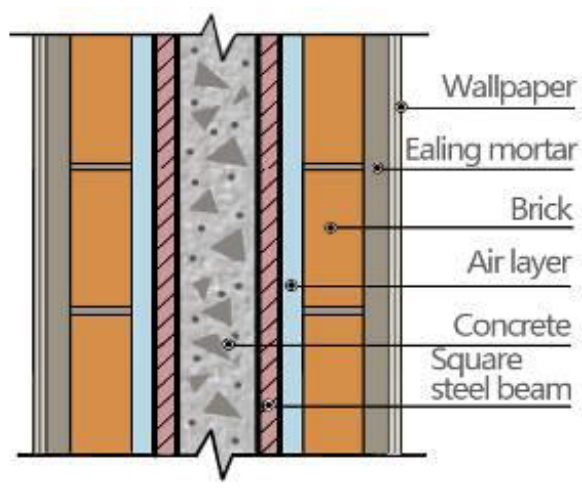

Figure 8. Section of Steel Structure and Building Enclosure

Regarding the supply of heat, and according to the co-existence coupling relationship between the dwellers and hardware of the thermal environment, some extent of the cultural features of the Kang in northeastern China was maintained. Inheriting and applying the heat-supplying principle from the food preparation process, the co-existence coupling design between the Kang, the smoke tunnel, the fire wall and the oven has been explored. However, the established connection mode between the Kang and the oven was eliminated by the electrically heated Kang being separated from the high-platform oven, as shown in Figure 9, which can lead to the farmers being able to cook their meals comfortably without bending forward; the large cooking pans could be smaller in size, furthermore, the previous elementary cooking technique, for example, where every dish is prepared with one pot and the stew-based diet structure could be modified into more delicate and varied techniques.

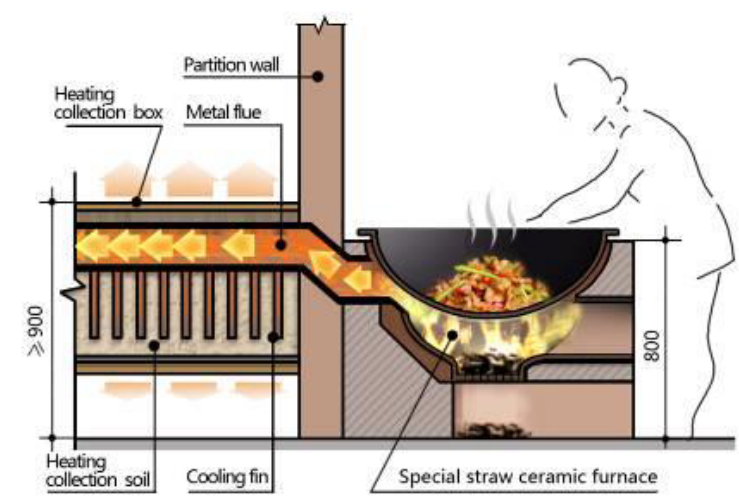

4.4 Figure 9. Section of New Kang-ovenEnergy Saving Design in Daily Life

The design for energy saving in daily life aimed at invoking a subconscious or conscious effort for farm- 


\section{MATEC Web of Conferences}

ers to conserve energy through the energy-living facilities and guidance on lifestyle changes.

The electric geothermal film in the living room and the electric Kang in the bedroom can perform independent thermal control, which is convenient for farmers to generate selectively heat energy in accordance with their actual activity areas. The effort in this work has shown the strain-reactive coupling design for accommodating behavior-conducive. In addition, the self-coupling design has been applied in the kitchen under the passive energy-application concept, including replacing the traditional underground cave (used only to store ingredients) with the cabinet built-in cellar and its supporting storage box, which can be lifted and lowered into position and represents a natural refrigerator (Figure 10); moreover, there are two pots of large and small size installed on the cooking bench: the small one available for daily cooking, and the other for the rough processing of crops and feed for backyard, and so on.

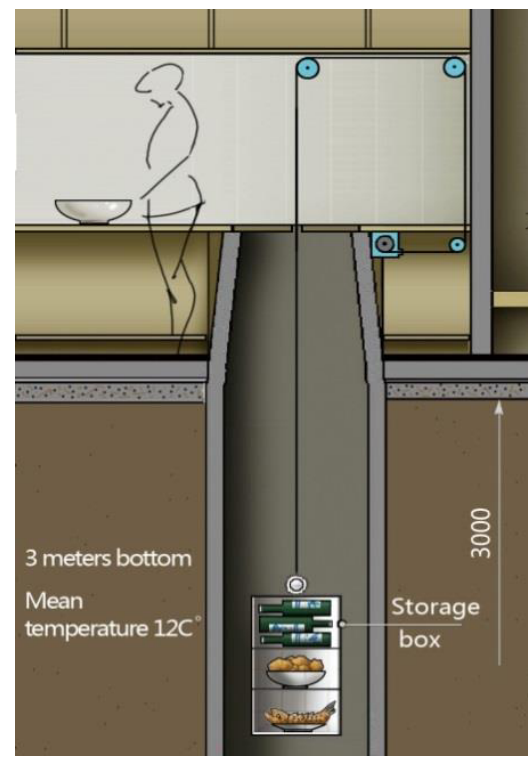

Figure 10. Section of Built-in Cabinet

Based on the coexistence relationship between the building and its dwellers, a potential-energy power-generating device which can be operated simply by revolving its handle (See in Figure 11) was employed to supply electricity for the daily consumption of the house.

We also designed an energy-saving bathroom to guide farmers toward conserving energy under subconscious behavior, such as a water-saving bathtub (Figure s12) with the capability of saving $50 \%$ of the water required for a normal family bathtub.

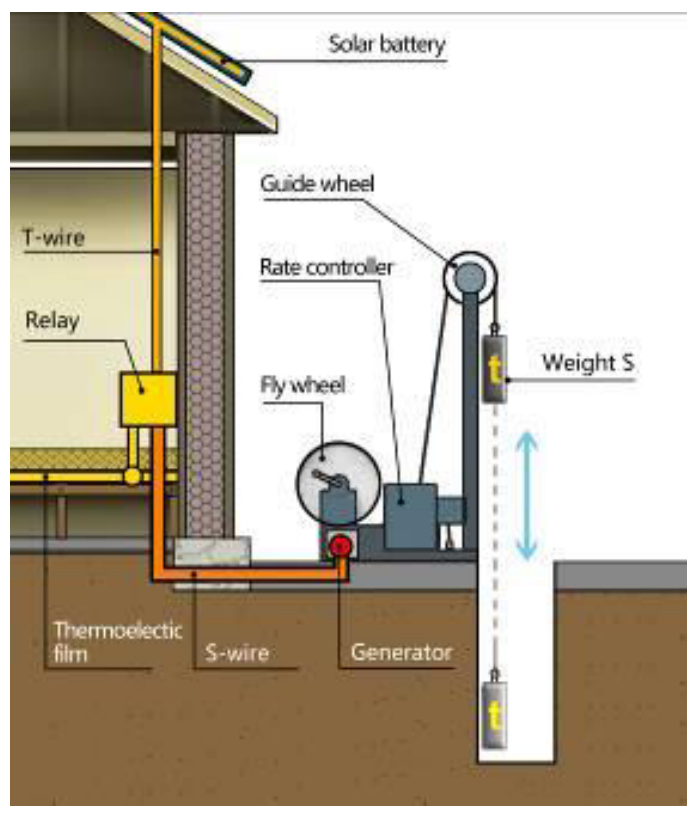

Figure 11. Section of Potential-energy Power-generating Device

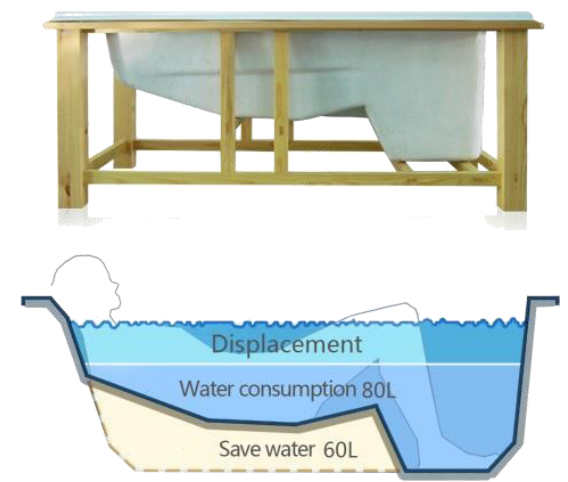

Figure 12. Prototype of Water-saving Bathtub

\subsection{Modeling of New Farmers}

The nature of modeling new farmers is to cultivate their behavior and disposition toward those typical of modern civilization, whereas they enjoy the material achievements of modernization. It is suggested that the first step is to eliminate the firewood-smell of farms to elevate their confidence and encourage a modern living style. Based on the self-coupling and strain-reactive coupling theory, a new type of hearth (Figure 9) has avoided flow of smoke into the inner 
rooms, while as the new kitchen has been positioned apart from the living space; the structure of which can restrict smoke flowing toward the interior; the closed smoke channels (Figure 13) and the fire walls can also prevent smoke from infiltrating through to the interior living spaces. The cultivation of civilized behavior in new farmers, in our opinion, is firstly concerned with personal hygiene and a sanitary living environment. For this purpose, some strain-reactive coupling designs based on behavior-conducive and ideas-conducive living have been explored, such as the hallway at the entrance door and installing a wardrobe and shoe storage for the convenience of changing coats and slippers. For the purpose of cultivating a modernized living style, we divided the functional space into a living room, multipurpose room, bedroom and sitting room, and so on. (Figure 13)

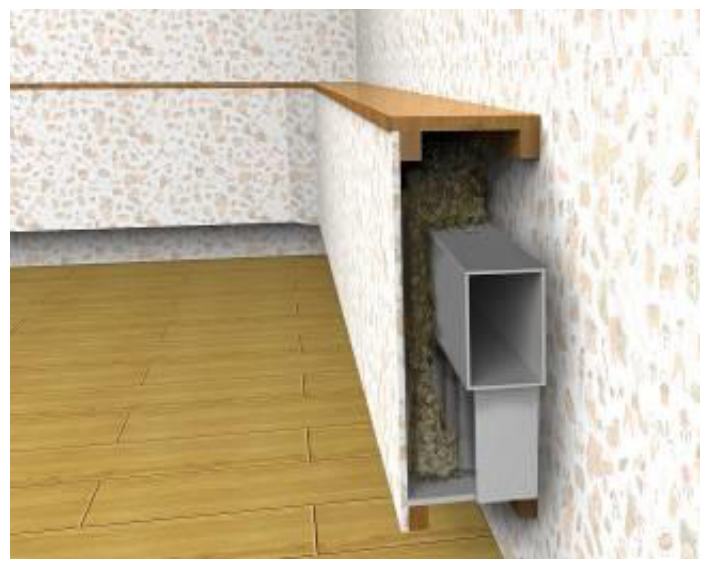

Figure 13. Prototype of Closed Smoke Channel.

\section{CONCLUSIONS}

In this study, the rural residential system is regarded as an interactive system including buildings, techniques and cultures. With the idea of rural livable construction based on the practice of humanistic values, we provide designers new assessment criteria for selection of architecture structure and techniques that is different from the conventional systems which only rely on physical indices and market evaluation. Livable residences not only satisfy formers' current demands, but also are favorable for the development of quality and personality. Only the humanistic values are considered as a standard for refurbishment of dilapidated buildings and are balanced with the hardware-software equilibrium in the coupling relationship, and the efficacy and value of hardware are meaningful and the livable level of residences are able to stand the social and environmental evaluations.

\section{ACKNOWLEDGEMENTS}

This research was supported by the Ministry of Construction (MOF), Housing and urban-rural funded by Dalian Nationalities University, China (20110003128).

\section{REFERENCES}

[1] Grove, A.T. \& Ren, Y. 2005. The circular economy in China, Journal of Material Cycles and Waste Management. 9(2): 121-129.

[2] Yuan, Z.T. \& Long, L. 2011. Low-energy architectural design strategies based on original-ecological construct system of vernacular architecture in western Hunan, Business Management and Electronic Information. 2011 International Conference on Business Management and Electronic Information (BMEI 2011) 4: 863-865. Guangzhou: China.

[3] Zhu, G.Y. \& Hang, Z. 1999. Issues in historical village conservation and development. Architectural Journal, 4: 56-57.

[4] Bai X.C., Zhang Y.Z. \& He Z.Q. 2010. Resources in Construction of new socialism countryside: A case study on the Yuxi Areas, Henan Province, Resources Science, 32(9): 1792-1798.

[5] Nagy, Z., Rossi, D. \& Schlueter, A. 2012. Sustainable architecture and human comfort through adaptive distributed systems, 2012 IEEE International Conference on Pervasive Computing and Communications Workshops (PerCom Workshops). Lugano: Switzerland. pp: 403-406.

[6] Yoshizaka, T. 1984. Discovery of Reside, Tokyo: Keiso Shobo.

[7] Von Bertalanff, L. 1973. General system theory: foundations, development, applications. Rev. Ed. George Braziller.

[8] Liu, W.H. 2009. Study on Rural House Technology System Design Based on Renewable Energy Utilization, Harbin: Harbin Institute of Technology, pp: 26-31.

[9] Naess, A. 1995. Self-realization: an ecological approach to Being in the world. The deep ecology movement: $A n$ introductory anthology: 13-30.

[10] Li, X.X. 2005. Technology System Theory, Beijing: Science Press. 